\title{
Lethal and Sublethal Effects of Various Pesticides on Trichogramma achaeae (Hymenoptera: Trichogrammatidae)
}

\author{
João Fontes, ${ }^{1}$ Inés Sanchez Roja, ${ }^{1}$ João Tavares, ${ }^{2}$ and Luísa Oliveira ${ }^{2,3}$ \\ 'Faculdade de Ciências e Tecnologias, Universidade dos Açores, Rua da Mãe de Deus, 9501-801 Ponta Delgada, S. Miguel, Açores, \\ Portugal, 'Faculdade de Ciências e Tecnologias, Centro de Biotecnologia dos Açores, Universidade dos Açores, Rua da Mãe de \\ Deus, 9501-801 Ponta Delgada, S. Miguel, Açores, Portugal, and 3Corresponding author, e-mail: maria.Im.oliveira@uac.pt
}

Subject Editor: Eric Riddick

Received 16 October 2017; Editorial decision 24 February 2018

\begin{abstract}
Little information is available regarding the lethal and sublethal effects of pesticides on Trichogramma achaeae (Nagaraja and Nagarkatti; Hymenoptera: Tricogrammatidae) during integrated management of Tuta absoluta (Meyrick; Lepidoptera: Gelechiidae), an important pest for tomato production. Twenty-two pesticides sprayed on Ephestia kuehniella (Zeller; Lepidoptera: Pyralidae) eggs were evaluated on the mortality of adult parasitoids upon contact with the hosts $24 \mathrm{~h}$ after the treatments and their sublethal effects on the parasitoids were assessed in laboratory conditions. Tests were carried out with fresh solutions at the recommended concentration. According to the International Organisation for Biological and Integrated Control (IOBC) standards, chlorpyrifos is harmful to the parasitoid; merthiocarb, methomyl, spinosad lambda-cyhalothrin, and acrinatrin are moderately harmful; and chlorantraniliprole, lufenuron, hexythiazox, cyromazine and Bacillus thuringiensis have no effect on the parasitoid. Sulfur is slightly harmful, and azoxystrobin is harmless. Chlorpyrifos was the most lethal among these pesticides and killed all females in less than $24 \mathrm{~h}$. All other pesticides affected the biological parameters of $T$. achaeae to varying degrees. Regarding the lethal and sublethal effects, merthiocarb and spinosad killed all female offspring in less than $24 \mathrm{~h}$; lambda-cyhalothrin and sulfur reduced the number of parasitized eggs; and acrinatrin, deltamethrin and azoxystrobin affected the emergence rate. After that, we can recommend the use of chlorantraniliprole and B. thuringiensis to control Lepidoptera, cyromazine to control Diptera, pirimicarb to control Homoptera, hexythiazox to control mites and azoxystrobin can be used as fungicide in an integrated pest management program with mass released of $T$. achaeae.
\end{abstract}

Key words: pesticide, integrated pest management, egg parasitoid, toxicity, side effect

A combination of biological and chemical control approaches is very important for a successful integrated pest management (IPM) programs (Musser et al. 2006, Ghorbani et al. 2016). IPM programs use a combination of strategies, such as chemical, biological, and mechanical control, to maintain pest populations below economic thresholds (Roubos et al. 2014, Khan et al. 2015). The use of pesticides that are effective against target pests but have little or no negative effects on their natural enemies are desirable (Bastos et al. 2006, Preetha et al. 2010). Although biological control is very important in pest control, chemical control is still needed when there is a pest outbreak that produces an economic loss.

The negative effects of pesticides on natural enemies induce the necessity to study their side effects to adjust chemical and biological control programs and reduce the negative impacts of pesticides on non-target organisms (Souza et al. 2014, Ghorbani et al.
2016). Pesticides have lethal and sublethal effects on arthropods, as they can kill these organisms or negatively affect various biological parameters (Desneux et al. 2007, Garcia et al. 2009, Cordeiro et al. 2010, Castro et al. 2012).

Tomato (Solanum lycopersicum L.) is a major agricultural crop, with an estimated production of 170,751 MT year ${ }^{-1}$ (FAOSTAT 2014). Tomato crops are exposed to numerous pest organisms that cause economic losses, and the use of pesticides is necessary when they reach the economic threshold.

Tuta absoluta (Meyrick; Lepidoptera: Gelechiidae) is considered one of the most important pests for tomato production and results in serious damage in infested areas in different countries of the world (Desneux et al. 2011). The egg parasitoid Trichogramma achaeae (Nagaraja and Nagarkatti; Hymenoptera: Tricogrammatidae) was identified as an agent for the biological control of T. absoluta in the 
Palaearctic region (Polaszek et al. 2012). Nevertheless, one method for the protection of these parasitoids is to use selective insecticides and fungicides, as well as other chemical and/or biological agents that are harmless to these organisms.

A combined use of parasitoid releases and safe pesticide products will maximize the impact of their use in pest control as tomato cultivation requires pesticides to be applied for protection against other pests and diseases, such as flies, whiteflies, spider mites and fungi (Momanyi et al. 2012).

Regardless of literature available on the effects of pesticides on Trichogramma spp. (Cônsoli et al. 2001, Garcia et al. 2009, Blibech et al. 2015), there is information on the adverse effects of the most commonly used pesticides regularly used in tomato crops on the eggs parasitoid T. achaeae, which are used in mass releases to control T. absoluta. Several studies have shown that Trichogramma spp. are very vulnerable to a large variety of pesticides (Hassan et al. 1998, Vieira et al. 2001, Khan et al. 2015).

This study aimed to evaluate the negative effects of $22 \mathrm{com}$ monly used pesticides ( 20 insecticides or acaricides and 2 fungicides) in greenhouse tomato crops in Azores, on biological parameters of T. achaeae. We also analyzed the sublethal effects on the offspring.

\section{Materials and Methods}

\section{Insects}

Tr. achaeae were originally collected from eggs of Thysanoplusia orichalcea (Fabricius) and Chrysodeixis calcites (Esper; Lepidoptera: Noctuidae) found at Chã da Macela, São Miguel Island, Azores (Portugal) (37 $75^{\prime} 87^{\prime \prime} \mathrm{N}, 25^{\circ} 54^{\prime} 12^{\prime \prime} \mathrm{O}$, at $253 \mathrm{~m}$ altitude) and maintained in laboratory conditions on Ephestia kuehniella (Zeller; Lepidoptera: Pyralidae) eggs for 5-7 generations. Parasitoids were reared on E. kuehniella, glued onto yellow cardboard $(0.8 \times 8.5 \mathrm{~cm})$ with the aid of $30 \%(w / v)$ gum Arabic, in glass tube $(10.0 \times 1.0 \mathrm{~cm}$ diameter) containing honey droplets as a source of food for emerged adult. The glass tubes were closed with cotton wool and maintained at $21 \pm 1^{\circ} \mathrm{C}$ of temperature, $70 \pm 5 \%$ relative humidity $(\mathrm{RH})$ and with a natural photoperiod $(11.9 \pm 3.6 \mathrm{~h} \mathrm{Light})$.

\section{Pesticides}

All tests were performed with fresh solutions of commercial pesticides prepared in water. Twenty insecticides and two fungicides were tested at the concentrations recommended by the manufacturer as indicated in Table 1. Pesticides were selected based on their use for the control of different pests in tomato greenhouses in the Azores archipelago.

\section{Toxicity of Dried Pesticide Residues to Tr. achaeae Adults}

For analysis of the effect of the various pesticides on the mortality of females and on other biological parameters of T. achaeae, yellow cards $(1.5 \times 0.8 \mathrm{~cm})$ were prepared, each with 500 UV-killed E. kuebniella eggs glued to the card with a $30 \%$ solution of Arabic glue. The experiment design follows the guidelines of the International Organisation for Biological and Integrated Control (IOBC) for exposure of parasitoids to pesticides. The assay was performed in two different periods of time (group A and group B), with one control for each group. Every treatment was repeated four or five times, depending on the mortality of the females, and there were 15 replicates, corresponding to 15 host egg cards, sprayed with one of the 22 pesticides or with water ( $n=60-75$ per treatment). Each set of host egg cards was sprayed with $6 \mathrm{ml}$ of an aqueous suspension of one of the pesticides, using Potter tower equipment (Burkard, Rickmansworth, United Kingdom) at 2 bars. Controls were sprayed with distilled water. This resulted in homogeneous spray coverage of $9.52 \pm 2.17 \mu \mathrm{l}($ mean $\pm \mathrm{SD})$ of fluid $\mathrm{cm}^{-2}$, corresponding to the concentrations recommended by the manufacturer $\left(1,000 \mathrm{l} \mathrm{ha}^{-1}=10 \mu \mathrm{l}\right.$ $\mathrm{cm}^{-2}$ ). After treatment, egg cards were air-dried in an open plastic box for $24 \mathrm{~h}$, and then they were offered to one isolated T. achaeae female, with less than $24 \mathrm{~h}$ of life, into the glass tube. The female was supplied with a honey solution $(50 \%)$ and allowed to parasitize until her death. Females were observed daily until death to calculate

Table 1. Pesticides tested and their used and recommended field rates used in the experiment

\begin{tabular}{|c|c|c|c|c|c|}
\hline Active ingredient (a.i.) & Chemical group & $\begin{array}{l}\text { Trade name with } \\
\text { formulation }\end{array}$ & Used & Company & Dose $/ \mathrm{cm}^{2}$ \\
\hline Abamectin & Avermectin & Bermectine $1.8 \mathrm{EC}$ & Insecticide/acaricide & SIPCAM Portugal & $0.005 \mu \mathrm{l}$ \\
\hline Acetamiprid & Neonicotinoid & Epik 20 SG & Insecticide & SIPCAM Portugal & $0.005 \mathrm{mg}$ \\
\hline Acrinatrin & Pyrethroid & Rufast Avance 75 EW & Insecticide & SELECTIS & $0.006 \mu \mathrm{l}$ \\
\hline Azoxystrobin & Strobilurin & Ortiva $23.1 \mathrm{SC}$ & Fungicide & SYNGENTA & $0.010 \mu \mathrm{l}$ \\
\hline $\begin{array}{l}\text { Bacillus thuringiensis subsp. } \\
\text { Kurstaki }\end{array}$ & Microbiological & Bactil X2 6.4 WP & Insecticide & SIPCAM Portugal & $0.005 \mathrm{mg}$ \\
\hline Chlorantraniliprole & Anthranilic diamide & Altacor $35 \mathrm{WG}$ & Insecticide & Bayer CropScience Portugal & $0.001 \mathrm{mg}$ \\
\hline Chlorpyrifos & Organophosphate & Destroyer 480 EC & Insecticide & Nufarm Portugal & $0.020 \mu \mathrm{l}$ \\
\hline Cyromazine & Triazine & Trigard 75 WP & Insecticide & SYNGENTA & $0.003 \mathrm{mg}$ \\
\hline Deltamethrin & Pyrethroid & Decis $25 \mathrm{EC}$ & Insecticide & Bayer CropScience Portugal & $0.005 \mu \mathrm{l}$ \\
\hline Emamectin Benzoate & Avermectin & Affirm 0.85 SG & Insecticide & SYNGENTA & $0.015 \mathrm{mg}$ \\
\hline Hexythiazox & Carboxamide & Nisorum $10 \mathrm{WP}$ & Acaricide & SIPCAM Portugal & $0.005 \mathrm{mg}$ \\
\hline Imidacloprid & Neonicotinoid & Confidor 200 SL & Insecticide & Bayer CropScience Portugal & $0.005 \mu \mathrm{l}$ \\
\hline Lambda-cyhalothrin & Pyrethroid & Atlas $9.5 \mathrm{SC}$ & Insecticide & SELECTIS & $0.003 \mu \mathrm{l}$ \\
\hline Lufenuron & Benzoylurea & Match $0.50 \mathrm{EC}$ & Insecticide & SYNGENTA & $0.020 \mu \mathrm{l}$ \\
\hline Merthiocarb & Carbamate & Mesurol 200 SC & Insecticide & Bayer CropScience Portugal & $0.050 \mu \mathrm{l}$ \\
\hline Methomyl & Carbamate & Lannate $25 \mathrm{WP}$ & Insecticide & DU PONT-SAPEC & $0.013 \mu \mathrm{l}$ \\
\hline Neem oil & Limonoid & Neem EC & Insecticide & BIAGRO & $1.000 \mu \mathrm{l}$ \\
\hline Pirimicarb & Carbamate & Pirimor $50 \mathrm{WG}$ & Insecticide & SYNGENTA & $0.005 \mathrm{mg}$ \\
\hline Spinosad & Spinosyn & Spintor $480 \mathrm{SC}$ & Insecticide & Lusosem & $0.003 \mu \mathrm{l}$ \\
\hline Sulfur & Inorganic & Stullun $80 \mathrm{WG}$ & Fungicide & SAPEC Agro Portugal & $0.040 \mathrm{mg}$ \\
\hline Thiamethoxam & Neonicotinoid & Actara $25 \mathrm{WG}$ & Insecticide & SYNGENTA & $0.003 \mathrm{mg}$ \\
\hline Vegetable oils & - & Vegetable oil soap & Insecticide & Natur chemís & $1.000 \mu \mathrm{l}$ \\
\hline
\end{tabular}


the longevity of adults in contact with the treated eggs. For the two groups, after offspring emergence, development time (egg to adult), number of parasitized eggs (host eggs that turned black), emergence rate (number of host eggs with a hole made by Trichogramma/total number of parasitized eggs) and sex ratio of offspring (number of females/total number of adults) were quantified for each treatment.

All tests were performed under semi-controlled conditions, at $26 \pm 1^{\circ} \mathrm{C}$ for group $\mathrm{A}$ and $23 \pm 1^{\circ} \mathrm{C}$ for group $\mathrm{B}$, in $70 \pm 5 \% \mathrm{RH}$ and with a natural photoperiod $(13.3 \pm 1.3 \mathrm{~h} \mathrm{Light})$.

\section{Effects on the First Generation}

After emergence, female offspring were isolated in a glass tube, and a yellow card with untreated E. kuehniella eggs and a small drop of honey solution was added. Parasitism was allowed for $7 \mathrm{~d}$. Then, the female was removed, and the mortality rate was recorded. Once the progenitor was removed, the egg cards were kept until the end of development in the same conditions. The estimated parameters were progenitor mortality rate, development time, number of parasitized eggs, emergence rate, and sex ratio of the offspring.

\section{Statistical Analysis}

Differences between treatments and the water control in female longevity, parasitoid development times, and number of parasitized host eggs that turned black were determined by a T-test using $\sqrt{ }(\mathrm{x}+$ $0.5)$-transformed data. Adult emergence rates and sex ratio were analyzed by $\mathrm{T}$-test using arcsine $\sqrt{ } \mathrm{x}$-transformed data to normalize their distribution (Zar 1996). Female infertility rates and female offspring mortality $7 \mathrm{~d}$ after emergence were analyzed by chi-square $\left(\chi^{2}\right)$ tests for comparison of proportions $(P<0.05)$. All analyses were performed using the statistical software SPSS 23.0 (IBM SPSS 2015).

Furthermore, the reduction in T. achaeae parasitism as related to the control treatment was calculated by the following equation: $E(\%)=(1-\mathrm{Vt} / \mathrm{Vc}) \times 100$, in which $E(\%)$ is the percent reduction in parasitism, $\mathrm{Vt}$ is the median parasitism for the treatment tested, and $\mathrm{Vc}_{\mathrm{c}}$ is the average parasitism observed for the control treatment (Carmo et al. 2010). The chemicals were classified according to the IOBC standards as follows: class 1, harmless $(E<30 \%)$; class 2 , slightly harmful $(30 \% \leq E \leq 79 \%)$; class 3 , moderately harmful $(80 \% \leq E \leq 99 \%)$; and class 4, harmful $(E>99 \%)$ (Hassan 1992$)$.

\section{Results}

\section{Toxicity of Dried Pesticide Residues to Tr. achaeae Adults}

Among all the tested products, chlorpyrifos was the most poisonous; it significantly reducing the female's longevity and completely prevented the attainment of offspring (Table 2).

Most of the products tested affected the longevity of the females after contact with the eggs treated 24 h earlier, with the exception of chlorantraniliprole, lufenuron, B. thuringiensis, cyromazine and azoxystrobin, and eight of them reduced the longevity of females to less than $2 \mathrm{~d}$ (Table 2). The percentage of females that did not exhibit black host eggs (female infertility) was variable, and the most harmful products were chlorpyrifos, merthiocarb, spinosad, acrinatrin,

Table 2. Mean ( \pm SE) female longevity, female infertility rate, development time (egg to adult), number of parasitized host eggs that turned black, emergence rate and female sex ratio of offspring of $T$. achaeae, when parasitism occurred $24 \mathrm{~h}$ after the host eggs were treated with 23 pesticides

\begin{tabular}{|c|c|c|c|c|c|c|}
\hline Treatment (a.i.) & $\begin{array}{l}\text { Female longevity } \\
\text { (days) }\end{array}$ & $\begin{array}{c}\text { Female infertilily } \\
(\%) \#\end{array}$ & $\begin{array}{l}\text { Development time } \\
\text { (days) }\end{array}$ & Parasitized egg $(n)$ & $\begin{array}{c}\text { Emergence rate } \\
(\%)\end{array}$ & $\begin{array}{c}\text { Female sex ratio } \\
(\%)\end{array}$ \\
\hline \multicolumn{7}{|l|}{ Group A } \\
\hline Abamectin & $2.45 \pm 0.2^{*}$ & $38.2 *$ & $9.1 \pm 0.1 *$ & $9.4 \pm 1.3 *$ & $54.6 \pm 3.4^{*}$ & $71.0 \pm 5.5$ \\
\hline Acetamiprid & $6.6 \pm 0.4^{*}$ & 20.0 & $9.5 \pm 0.1$ & $16.6 \pm 1.7^{*}$ & $89.8 \pm 2.4$ & $72.4 \pm 3.3$ \\
\hline Acrinatrin & $1.6 \pm 0.2 *$ & $68.0 *$ & $10.0 \pm 0.2$ & $0.6 \pm 0.1^{*}$ & $90.1 \pm 5.9$ & $83.8 \pm 6.2^{*}$ \\
\hline B. thuringiensis & $7.2 \pm 0.5$ & 21.8 & $9.5 \pm 0.1$ & $21.7 \pm 2.1$ & $94.0 \pm 0.9^{*}$ & $61.5 \pm 4.1$ \\
\hline Chlorantraniliprole & $7.2 \pm 0.5$ & 14.5 & $9.5 \pm 0.1$ & $22.4 \pm 2.3$ & $94.1 \pm 1.0^{*}$ & $71.4 \pm 3.5$ \\
\hline Chlorpyrifos & $<1.0 \pm 0.0^{*}$ & - & - & $0.0 \pm 0.0 *$ & - & - \\
\hline Deltamethrin & $6.5 \pm 0.5 *$ & 23.6 & $10.2 \pm 0.2$ & $5.8 \pm 0.8^{*}$ & $90.9 \pm 2.0$ & $90.3 \pm 3.3^{*}$ \\
\hline Emamectin & $1.9 \pm 0.1^{*}$ & $49.3 *$ & $9.3 \pm 0.1$ & $7.3 \pm 1.0 *$ & $84.7 \pm 2.3$ & $74.5 \pm 3.6$ \\
\hline \multicolumn{7}{|l|}{ Benzoate } \\
\hline Hexythiazox & $6.8 \pm 0.4 *$ & 10.9 & $9.4 \pm 0.1$ & $22.4 \pm 1.8$ & $92.1 \pm 2.2$ & $62.8 \pm 4.0$ \\
\hline Imidacloprid & $1.8 \pm 0.1^{*}$ & $38.7 *$ & $9.0 \pm 0.1^{*}$ & $11.0 \pm 1.2^{*}$ & $89.3 \pm 1.3$ & $74.8 \pm 2.9$ \\
\hline $\begin{array}{l}\text { Lambda- } \\
\text { cyhalothrin }\end{array}$ & $5.3 \pm 0.5^{*}$ & 30.9 & $10.1 \pm 0.2$ & $4.6 \pm 0.6^{*}$ & $94.2 \pm 1.52 *$ & $78.6 \pm 5.1^{*}$ \\
\hline Lufenuron & $7.3 \pm 0.5$ & 10.9 & $9.5 \pm 0.2$ & $23.5 \pm 2.1$ & $49.2 \pm 4.6^{*}$ & $70.9 \pm 4.1$ \\
\hline Merthiocarb & $1.0 \pm 0.0 *$ & $77.3 *$ & $10.2 \pm 0.3$ & $0.5 \pm 0.1^{*}$ & $36.3 \pm 10.0^{*}$ & $62.0 \pm 8.6$ \\
\hline Methomyl & $1.2 \pm 0.1 *$ & $42.7 *$ & $9.2 \pm 0.1$ & $5.1 \pm 0.7^{*}$ & $86.9 \pm 2.2$ & $73.9 \pm 4.9$ \\
\hline Neem oil & $5.9 \pm 0.5^{*}$ & 16.4 & $9.8 \pm 0.2$ & $14.6 \pm 1.3^{*}$ & $88.2 \pm 1.8$ & $75.4 \pm 3.9$ \\
\hline Pirimicarb & $6.1 \pm 0.5^{*}$ & 16.4 & $9.4 \pm 0.2$ & $18.5 \pm 1.5$ & $93.6 \pm 1.5^{*}$ & $66.8 \pm 3.7$ \\
\hline Spinosad & $1.1 \pm 0.0 *$ & $74.7^{*}$ & $10.0 \pm 0.3$ & $1.8 \pm 0.4^{*}$ & $14.9 \pm 3.9^{*}$ & $66.4 \pm 9.7$ \\
\hline Thiamethoxam & $2.2 \pm 0.2 *$ & $52.0^{*}$ & $9.1 \pm 0.1 *$ & $6.9 \pm 1.0^{*}$ & $86.8 \pm 2.0$ & $75.8 \pm 2.8^{*}$ \\
\hline Control & $8.2 \pm 0.4$ & 16.0 & $10.0 \pm 0.4$ & $26.7 \pm 1.7$ & $89.4 \pm 1.5$ & $66.3 \pm 3.2$ \\
\hline \multicolumn{7}{|l|}{ Group B } \\
\hline Azoxystrobin & $6.5 \pm 0.4$ & 8.3 & $12.6 \pm 0.1$ & $36.4 \pm 2.3$ & $89.9 \pm 1.2$ & $64.4 \pm 4.1$ \\
\hline Cyromazine & $7.4 \pm 0.4$ & 5.0 & $12.5 \pm 0.1$ & $34.0 \pm 2.14$ & $88.2 \pm 2.0^{*}$ & $63.5 \pm 3.8$ \\
\hline Sulfur & $1.9 \pm 0.1^{*}$ & 5.0 & $12.7 \pm 0.1^{*}$ & $18.9 \pm 1.2^{*}$ & $89.9 \pm 1.3$ & $74.8 \pm 4.0^{*}$ \\
\hline Vegetable oils & $3.5 \pm 0.3^{*}$ & 6.7 & $12.7 \pm 0.1^{*}$ & $22.4 \pm 1.4^{*}$ & $87.2 \pm 1.6^{*}$ & $68.9 \pm 4.2$ \\
\hline Control & $7.6 \pm 0.4$ & 8.3 & $12.4 \pm 0.1$ & $40.0 \pm 2.36$ & $93.2 \pm 1.1$ & $62.7 \pm 3.9$ \\
\hline
\end{tabular}

Treatments differing significantly (T-test or \# Chi-square $\left(\chi^{2}\right)$ test for comparison of proportions; $P<0.05$ ) from the water control are indicated by an asterisk (*). 
and thiamethoxam, which induced an infertility percentage greater than $50 \%$ (Table 2).

The results showed that only three pesticides significantly reduced the development time (abamectin, thiamethoxam and imidacloprid) (Table 2). Several tested pesticides caused a significant reduction in the number of parasitized host eggs, with the exception of chlorantraniliprole, lufenuron, pirimicarb, B. thuringiensis, hexythiazox, cyromazine and azoxystrobin, which resulted in rates of parasitisation equal or higher than the controls (Table 2). Merthiocarb, acrintrin, and spinosad resulted in less than two parasitized egg per female and chlorpyrifos none at all.

The emergence rate was significantly reduced by spinosad, followed by merthiocarb, lufenuron, and abamectin (Table 2). The three pyrethroids significantly affected the female sex ratio, with an increase in the number of females in the population (Table 2).

Consistent with these results, chlorpyrifos was the most toxic pesticide, reducing parasitism to zero, and was classified as harmful (class 4). Merthiocarb, methonil, lambda-cyhalothrinon, acrinatrin, and spinosad were moderately harmful (class 3 ). Only chlorantraniliprole, lufenuron, $B$. thuringiensis, hexythiazox, and cyromazine had no significant effect on the number of parasitized eggs (class 1) (Table 3). Data from the fungicide results showed that sulfur was classified as slightly harmful (class 2) and azoxystrobin as harmless (class 1) to T. achaeae (Table 3).

\section{Effects on the First Generation}

Analysis of the effects of merthiocarb, chlorpyrifos, and spinosad treatments was not performed, as the number of offspring females was very low, and they died in less than $24 \mathrm{~h}$.

Table 3. Placement of the pesticide into IOBC survival sideeffect classes based on the number of parasitized host eggs by T. achaeae that turned black, when parasitism occurred $24 \mathrm{~h}$ after the host eggs were treated with 22 compounds

\begin{tabular}{lrcl}
\hline Pesticide & $E(\%)$ & Class & \multicolumn{1}{c}{ Classification } \\
\hline Abamectin & 65 & 2 & Slightly harmful \\
Acetamiprid & 38 & 2 & Slightly harmful \\
Acrinatrin & 98 & 3 & Moderately harmful \\
Azoxystrobin & 9 & 1 & Harmless \\
Bacillus thuringiensis & 19 & 1 & Harmless \\
Chlorantraniliprole & 16 & 1 & Harmless \\
Chlorpyrifos & 100 & 4 & Harmful \\
Cyromazine & 15 & 1 & Harmless \\
Deltamethrin & 78 & 2 & Slightly harmful \\
Emamectin Benzoate & 73 & 2 & Slightly harmful \\
Hexythiazox & 16 & 1 & Harmless \\
Imidacloprid & 59 & 2 & Slightly harmful \\
Lambda-cyhalothrin & 83 & 3 & Moderately harmful \\
Lufenuron & 12 & 1 & Harmless \\
Merthiocarb & 98 & 3 & Moderately harmful \\
Methomyl & 81 & 3 & Moderately harmful \\
Neem oil & 45 & 2 & Slightly harmful \\
Pirimicarb & 31 & 2 & Slightly harmful \\
Spinosad & 93 & 3 & Moderately harmful \\
Sulfur & 53 & 2 & Slightly harmful \\
Thiamethoxam & 74 & 2 & Slightly harmful \\
Vegetable oils & 44 & 2 & Slightly harmful \\
\hline
\end{tabular}

$E(\%)=(1-\mathrm{Vt} / \mathrm{Vc}) \times 100$, in which $\mathrm{E}$ is the effect of the pesticide on parasitism viability reduction compared to the control, $\mathrm{Vt}$ is the parasitism viability for the treatments and $\mathrm{Vc}_{\mathrm{c}}$ is the parasitism viability for the control. Class 1- harmless $(E<30 \%)$; 2- slightly harmful $(30 \%<E<79 \%)$; 3- moderately harmful $(80 \%<E<99 \%)$; and 4 - harmful $(E<99 \%)$.
Regarding the mortality of the females, the most dangerous products were emamectin benzoate, imidacloprid, lambda-cyhalothrin, acrinatrin, and neem oil, which caused more than $95 \%$ female mortality during the first $7 \mathrm{~d}$. However, lufenuron, acetamiprid, B. thuringiensis, cyromazine, vegetable oils, and azoxystrobin did not affect this parameter (Table 4). The development time was significantly reduced by chlorantraniliprole, abamectin, lufenuron, pirimicarb, emamectin benzoate, acrinatrin, hexythiazox, vegetable oils, and sulfur, while the emamectin benzoate increased significantly this parameter (Table 4).

Only emamectin benzoate, imidacloprid, lambda-cyhalothrin, and sulfur significantly reduced the mean number of parasitized eggs. The emergence rate was significantly affected, with an increase induced by imidacloprid, lambda-cyhalothrin, acrinatrin, and deltamethrin, not very relevant in biological terms, and a reduction by azoxystrobin (Table 4). The offspring female sex ratio was also significantly affected by some pesticides, with a reduction in the number of females caused by chlorantraniliprole, emamectin benzoate, vegetable oils and by the three pyrethroids (lambda-cyhalothrin, acrinatrin and deltamethrin) and an increase caused by azoxystrobin (Table 4).

\section{Discussion}

Tr. achaeae is a suitable biological agent for use in pest management programs against T. absoluta, an introduced pest species that is difficult to manage with insecticides alone in tomato greenhouses.

Most laboratory and field studies have shown that Trichogramma wasps are highly susceptible to broad-spectrum insecticides ( $\mathrm{Li}$ et al. 1986). Consequently, use of insecticides and Trichogramma has historically been considered incompatible.

The pesticide concentrations tested were equivalent to those recommended for field application. The toxic effects were assessed by measuring different biological parameters of T. achaeae exposed to residues on host eggs, $24 \mathrm{~h}$ after treatment.

A high degree of variation in the effects was found among classes of insecticides and among insecticides of the same class. Some classes of insecticides, such as the organophosphates, some carbamates, some pyrethroids and spinosad, showed little or no selectivity to the parasitoid species tested. Our study showed that different insecticides possessed significantly different risks to the T. achaeae adults, which may provide useful information for integration of biological control with pesticide control.

In the literature, organophosphate, carbamate, and synthetic pyrethroid insecticides are generally considered highly hazardous to biological control agents due to their broad-spectrum activity (Carmo et al. 2010, Cloyd 2012, Amaro et al. 2015).

Chlorpyrifos, an organophosphate, is one of the most widely used insecticides worldwide (Delpuech and Meyet 2003). Residual amounts of chlorpyrifos on the treated eggs are very toxic to T. achaeae as they caused high mortality in the wasps $(100 \%)$ in the $24 \mathrm{~h}$ after its application and reduced the parasitisation rate to zero. Therefore is classified as harmful (class 4). Amaro et al. (2015) also found a high mortality and a negative effect on the behavior of T. pretiosum. These results were expected because organophosphate compounds have been described as highly harmful to parasitoids (Hassan et al. 1998, Moura et al. 2005, Moura et al. 2006), and its use in IPM should be avoided (Amaro et al. 2015).

Other neurotoxic insecticides, such as carbamates (pirimicarb, methiocarb and methomyl), may be directly and indirectly more harmful to natural enemies than non-nerve toxin-type pesticides (Cloyd 2012). The present study showed that merthiocarb and 
Table 4. Female mortality rate after $7 \mathrm{~d}$ of parasitism, mean $( \pm \mathrm{SE}$ ) development time (egg to adult), number of parasitized host eggs that turned black, emergence rate and female sex ratio of offspring of $T$. achaeae, obtained from eggs treated with 19 pesticides

\begin{tabular}{|c|c|c|c|c|c|}
\hline Treatment (a.i.) & Female mortality (\%)\# & Development time (days) & Parasitized egg $(n)$ & Emergence rate $(\%)$ & Female sex ratio $(\%)$ \\
\hline \multicolumn{6}{|l|}{ Group A } \\
\hline Abamectin & $86.7^{*}$ & $9.1 \pm 0.0 *$ & $22.3 \pm 2.9$ & $91.8 \pm 1.6$ & $60.2 \pm 5.8$ \\
\hline Acetamiprid & 60.0 & $9.3 \pm 0.1$ & $23.3 \pm 2.6$ & $92.9 \pm 1.1$ & $54.1 \pm 5.5$ \\
\hline Acrinatrin & $100.0^{*}$ & $9.1 \pm 0.1 *$ & $19.9 \pm 5.4$ & $99.3 \pm 0.7^{*}$ & $23.0 \pm 10.9 *$ \\
\hline B. thuringiensis & 75.6 & $9.3 \pm 0.1$ & $24.9 \pm 2.5$ & $93.8 \pm 0.8$ & $55.9 \pm 4.4$ \\
\hline Chlorantraniliprole & $91.1 *$ & $9.2 \pm 0.1 *$ & $28.78 \pm 2.6$ & $91.4 \pm 1.1$ & $49.0 \pm 4.9^{*}$ \\
\hline Deltamethrin & $93.3 *$ & $9.3 \pm 0.1$ & $30.3 \pm 2.7$ & $97.6 \pm 0.6^{*}$ & $11.4 \pm 4.7^{*}$ \\
\hline Emamectin Benzoate & $95.6^{*}$ & $10.0 \pm 0.1^{*}$ & $18.8 \pm 2.9^{*}$ & $88.4 \pm 3.5$ & $31.9 \pm 5.9^{*}$ \\
\hline Hexythiazox & $93.3 *$ & $9.2 \pm 0.1^{*}$ & $25.4 \pm 3.2$ & $94.2 \pm 1.0$ & $58.6 \pm 4.0$ \\
\hline Imidacloprid & $97.8 *$ & $9.3 \pm 0.1$ & $18.8 \pm 2.7^{*}$ & $96.4 \pm 0.9^{*}$ & $71.0 \pm 6.3$ \\
\hline Lambda-cyhalothrin & $96.4 *$ & $9.3 \pm 0.2$ & $15.0 \pm 3.5^{*}$ & $96.6 \pm 1.3 *$ & $5.9 \pm 4.1 *$ \\
\hline Lufenuron & 75.6 & $9.1 \pm 0.1 *$ & $31.6 \pm 2.0$ & $94.6 \pm 0.7$ & $62.5 \pm 4.8$ \\
\hline Methomyl & $88.9^{*}$ & $9.3 \pm 0.1$ & $27.2 \pm 4.7$ & $92.8 \pm 1.5$ & $51.9 \pm 8.2$ \\
\hline Neem oil & $100.0^{*}$ & $9.3 \pm 0.1$ & $24.9 \pm 2.6$ & $92.7 \pm 1.5$ & $55.0 \pm 5.3$ \\
\hline Pirimicarb & $86.7^{*}$ & $9.1 \pm 0.1^{*}$ & $32.9 \pm 2.6$ & $93.7 \pm 0.9$ & $65.2 \pm 3.4$ \\
\hline Thiamethoxam & $88.9 *$ & $9.2 \pm 0.1 *$ & $32.2 \pm 3.0$ & $94.3 \pm 9.0$ & $52.2 \pm 6.2$ \\
\hline Control & 57.8 & $9.6 \pm 0.2$ & $27.5 \pm 2.7$ & $93.6 \pm 0.8 \mathrm{ab}$ & $67.0 \pm 3.9 c$ \\
\hline \multicolumn{6}{|l|}{ Group B } \\
\hline Azoxystrobin & 9.0 & $13.6 \pm 0.1$ & $53.9 \pm 2.3$ & $91.2 \pm 1.0^{*}$ & $60.6 \pm 4.4^{*}$ \\
\hline Cyromazine & 8.0 & $13.6 \pm 0.1$ & $60.5 \pm 2.1^{*}$ & $95.6 \pm 0.5$ & $52.4 \pm 4.8$ \\
\hline Sulfur & $41.0 *$ & $12.7 \pm 0.2 *$ & $20.9 \pm 4.2^{*}$ & $89.9 \pm 1.3^{*}$ & $22.8 \pm 8.8$ \\
\hline Vegetable oils & 19.0 & $13.2 \pm 0.1^{*}$ & $48.9 \pm 2.8$ & $95.1 \pm 0.5$ & $36.4 \pm 5.1$ \\
\hline Control & 11.0 & $13.5 \pm 0.1$ & $52.3 \pm 2.9$ & $95.2 \pm 0.8$ & $39.2 \pm 5.5$ \\
\hline
\end{tabular}

Treatments differing significantly (T-test or \# Chi-square $\left(\chi^{2}\right)$ test for comparison of proportions; $P<0.05$ ) from the water control are indicated by an asterisk $(*)$.

methomyl were moderately harmful, and pirimicarb was slightly harmful (class 2) based on their reduction of parasitisation. All of them severely affected the longevity of the females and the number of host eggs parasitized and significantly reduced the longevity of offspring populations. Merthiocarb and methomyl also increased female infertility rate. Different studies have reported that pirimicarb did not affect the biological parameters of T. pretiosum (Carvalho et al. 2001), however, other authors found that this product caused high mortality when adults of other parasitoids were exposed to dry residues or the direct spray method (Desneux et al. 2004, Moens et al. 2012). Bueno et al. (2008) demonstrated that methomyl significantly reduced parasitism viability when applied in the $T$. pretiosum immature stages.

Pyrethroids are the second most widely used family of insecticides (Delpuech and Delahaye 2013), however their application is not compatible with biological control methods, as shown in different studies (Beserra and Parra 2005, Carmo et al. 2010, Ksentini et al. 2010). In our study, pyrethroids were moderately harmful (class 3) to T. achaeae and notably reduced the longevity of females after contact with treated host eggs and the number of parasitized eggs, and acrinatrin significantly increased the percentage of infertile females. We also observed lethal and sublethal effects in the offspring. Beserra and Parra (2005), observed that different formulations of lambda-cyhalothrin, when applied before contact of the females with the host eggs, were harmful to T. pretiosum and Wang et al. (2012) showed that pyrethroids (cyhalothrin, fenpropathrin and lambda-cyhaltrin) are highly toxic to T. ostriniae adults. Very little is known about the effect of acrinatrin on Trichogramma species; however, the same author reported that acrinatrin is harmful to different parasitoid species. Concerning the effect of deltamethrin residues on Trichogramma adults, Ksentini et al. (2010) found them to be very harmful towards all Trichogramma species tested, and the same was observed by Bastos et al. (2006), Blibech et al. (2015), and Thubru et al. (2016).
Nowadays, neonicotinoids are the most widely used insecticidal class in the world (Jeschke and Nauen 2008, Simon-Delso et al. 2015), and are among the most effective insecticides for control of sucking and chewing herbivores (Tomizawa and Casida 2003). Some authors have suggested that some neonicotinoids may be used in combination with natural enemies in IPM programs (Millar and Denholm 2007, Pisa et al. 2017). However, in our study, we detected a significant reduction in the longevity of the females after contact with eggs treated with the assessed neonicotinoids and in the number of parasitized eggs, in treatments with thiamethoxam and imidacloprid. In this study, these neonicotinoids were classified as slightly harmful. Some authors have shown that thiamethoxam was harmful to other Trichogramma species, such as T. chilonis, T. platneri, and T. pretiosum (Brunner et al. 2001, Williams and Price 2004, Preetha et al. 2009). Imidacloprid has been found to be harmful to T. chilonis, T. cacoeciae, and T. nr. brassicae (Hewa-Kapuge et al. 2003, Saber 2011). Conversely, other authors indicated that acetamiprid is safe for T. pretiosum (Moura et al. 2005) and could be recommended in association with this species in tomato pest management programs (Moura et al. 2006).

As we observed, the harmlessness of chlorantraniliprole was also reported for different Trichogramma species, such as T. pretiosum, T. dendrolimi, T. chilonis, and T. japonicum and other species of parasitoid eggs (Preetha et al. 2009, Brugger et al. 2010, Uma et al. 2014).

Additionally, avermectin produced a high mortality of the females, increased the infertility of the females, and reduced the number of parasitized host eggs, and abamectin reduced the emergence rate of T. achaeae. The lethal and sublethal effect on the offspring population was evident in the female mortality rate, and when emamectin benzoate was used, we observed a reduction in the number of females in the population. Araújo et al. (2013) observed a reduction in the number of parasitized host eggs and placed abamectin in Class 2 for T. pretiosum in eggs of Sitotroga cerealella (Oliver; Lepidoptera: 
Gelechiidae), and Khan et al. (2015) reported that it was highly toxic to the same species. Hussain et al. (2010) found that abamectin and emamectin benzoate were harmful to T. chilonis adults after $24 \mathrm{~h}$ of exposure.

Lufenuron is classified as harmless; however, it affects the emergence rate of T. achaeae. This is a benzoylphenylurea compound and acts by inhibiting the production of chitin, showing some selectivity across insect taxonomic orders (Carmo et al. 2010). It was reported to have only mild side effects on Trichogramma species, such as T. dendrolimi (Takada et al. 2001), and T. cacoeciae (Hassan and Haves 1998). However, the emergence rate of T. achaeae was significantly reduced, as observed by Carmo et al. (2010) in a study with the egg parasitoid Telenomus remus (Nixon; Hymenoptera: Scelionidae).

Concerning spinosad, the high mortality values and the negative effect on biological parameters of T. achaeaae could be explained by its mode of action, similar to the observed with the neonicotinoids pesticides, which excites the nervous system by activating the nicotinic receptors of the acetylcholine, causing paralysis of the insects (Cônsoli et al. 2001). Similar results were observed by Ksentini et al. (2010) and Thubru et al. (2016), among others, in studies with different species of Trichogramma.

Our results showed that hexythiazox and cyromazine could be considered harmless to this egg parasitoid, consistent with the observations by Nadimi et al. (2008) in a study to evaluate the effect of hexythiazox (Nisorun, EC 10\%) on Phytoseiulus persimilis (Evans; Acari: Phytoseiidae). Lira et al. (2015) reported a low acute toxicity of hexythiazox on Tamarixia radiata (Waterston; Hemiptera: Eulophidae), an important ectoparasitoid of Diaphorina citri (Kuwayama; Hemiptera: Liviidae). Hassan (1994) also reported the harmless effect of cyromazine on T. cacoeciae.

Based on a lack of toxicity and no apparent lethal and sublethal effects, it seems acceptable to assume that B. thuringiensis products, soap and oil could be successfully integrated into a biological control program unless these products are used in conjunction with small parasitoids (Brunner et al. 2001). Numerous studies have shown that $B$. thuringiensis is harmless to Trichogramma species (Vieira et al. 2001, Zhu et al. 2009, Thrubru et al. 2016). Among all 22 pesticides evaluated, neem oil reduced the longevity of the females and the number of parasitized host eggs by $T$. achaeae, and caused a very high mortality of their offspring. El-Wakeil et al. (2006) reported that neem products reduced the parasitism rate of T. pretiosum and had minor side effects on T. minutum, and Khattak and Mamoon-ur-Rashid (2006) observed that neem oil affected the parasitization of bollworm eggs by T. chilonis. Burnner et al. (2001) observed mortality of T. platneri when exposed to sprays of soap and suggested that was due to physical properties of the formulations, and mortality was caused by the adhesion of wings, legs, and antennae to the body.

In our study, both fungicides tested were harmless or only slightly harmful to T. achaeae, as observed by other authors for the same genus (Pratissoli et al. 2010, Silva and Bueno 2015) or in other egg parasitoids. According to Pratissoli et al. (2010), the fungicide azoxystrobin was selective to T. atopovirilia and can be used in integrated management of diseases in cucurbitaceous crops. Nevertheless, sulfur was slightly harmful to T. achaeae, with negative effects on female longevity and in the number on parasitized host eggs and lethal and sublethal effects on the offspring. Thomson et al. (2001) considered sulfur harmful to adults and to immature stages of two Trichogramma species ( $T$. carverae, $T$. funiculatum) and suggested that to reduce the impact on resident Trichogramma, other chemicals will need to be used.
According to our results, we suggest the used of chlorantraniliprole and B. thuringiensis to control Lepidoptera as T. absoluta and caterpillars, cyromazine to control Diptera as Liriomyza buidobrensis (Blanchard; Diptera: Agromyzidae) and other miners, pirimicarb to control Homoptera as aphids, hexythiazox to control mites and azoxystrobin to control fungus in an IPM program with mass released of T. achaeae. However, the insecticides usually used to control with flies, one of the major pests in tomato crops, showed to be toxic to T. achaeae.

\section{Acknowledgments}

We thank João Botelho and António Custódio for providing the pesticides used in this study.

\section{References Cited}

Amaro, J. T., A. F. Bueno, A. F. Pomari-Fernandes, and P. M. Neves. 2015. Selectivity of organic products to Trichogramma pretiosum Riley (Hymenoptera: Trichogrammatidae). Neotrop. Entomol. 44: 489-497.

Araújo, E. S., D. P. Targão, P. L. Pastori, and L. B. Monteiro. 2013. Seletivity of phytossanity products to Trichogramma pretiosum (Hymenoptera: Trichogrammatidae) collected in apple leafroller eggs, Bonagota salubricola (Meyrick, 1937) (Lepidoptera: Tortricidae) in Fraiburg, Brazil. Scientia Agraria, Curitiba, Brazil, 14: 35-39.

Bastos, C. C., R. P. Almeida, and F. A. Suinaga. 2006. Selectivity of pesticides used on cotton (Gossypium hirsutum) to Trichogramma pretiosum reared on two laboratory-reared hosts. Pest Manag. Sci. 62: 91-98.

Beserra, E. B., and J. R. P. Parra. 2005. Selectivity of lambda-cyhalothrin to Trichogramma pretiosum Riley, 1879 (Hymenoptera: Trichogrammatidae). Acta Sci. Agron. 27: 321-326.

Blibech, I., M. Ksantini, T. Jardak, and M. Bouaziz. 2015. Effect of insecticides on Trichogramma Parasitoids used in biological control against Prays oleae insect pest. Adv. Chem. Engineer. Sci. 5: 362-372.

Brugger, K. E., P. G. Cole, I. C. Newman, N. Parker, B. Scholz, P. Suvagia, G. Walker, and T. G. Hammond. 2010. Selectivity of chlorantraniliprole to parasitoid wasps. Pest Manag. Sci. 66: 1075-1081.

Brunner, J. F., J. E. Dunley, M. D. Doerr, and E. H. Beers. 2001. Effect of pesticides on Colpoclypeus florus (Hymenoptera: Eulophidae) and Trichogramma platneri (Hymenoptera: Trichogrammatidae), parasitoids of leafrollers in Washington. J. Econ. Entomol. 94: 1075-1084.

Bueno, A., R. C. O. F. Bueno, J. R. P. Parra, and S. S. Vieira. 2008. Effects of pesticides used in soybean crops to the egg parasitoid Trichogramma pretiosum. Ciênc. Rural. 38: 1495-1503.

Carmo, E. I., A. F. Bueno, and R. C. O. F. Bueno. 2010. Pesticide selectivity for the insect egg parasitoid Telenomus remus. BioControl. 55: 455-464.

Carvalho, G. A., J. R. P. Parra, and G. C. Baptista. 2001. Seletividade de alguns produtos fitossanitários a duas linhagens de Trichogramma pretiosum Riley, 1879 (Hymenoptera: Trichogrammatidae). Cien. Agrotec. Lavras. 25: 583-591.

Castro, A. A., M. C. Lacerda, T. V. Zanuncio, F. de S Ramalho, R. A. Polanczyk, J. E. Serrão, and J. C. Zanuncio. 2012. Effect of the insect growth regulator diflubenzuron on the predator Podisus nigrispinus (Heteroptera: Pentatomidae). Ecotoxicology. 21: 96-103.

Cloyd, R. A. 2012. Indirect effects of pesticides on natural enemies, pp. 127150. In R. P. Soundararajan (ed.), Pesticides: advances in chemical and botanical pesticides, InTech, Rijeka, Croatia.

Cônsoli, F. L., P. S. M. Botelho, and J. R. P. Parra. 2001. Selectivity of insecticides to the egg parasitoid Trichogramma galloi Zucchi, 1988 (Hym., Trichogrammatidae). J. Appl. Entomol. 125: 37-43.

Cordeiro, E. M., A. S. Corrêa, M. Venzon, and R. N. Guedes. 2010. Insecticide survival and behavioral avoidance in the lacewings Chrysoperla externa and Ceraeochrysa cubana. Chemosphere. 81: 1352-1357.

Delpuech, J. M., and M. Delahaye. 2013. The sublethal effects of deltamethrin on Trichogramma behaviors during the exploitation of host patches. Sci. Total Environ. 447: 274-279. 
Delpuech, J. M., and J. Meyet. 2003. Reduction in the sex ratio of the progeny of a parasitoid wasp (Trichogramma brassicae) surviving the insecticide chlorpyrifos. Arch. Environ. Contam. Toxicol. 45: 203-208.

Desneux, N., H. Rafalimanana, and L. Kaiser. 2004. Dose-response relationship in lethal and behavioural effects of different insecticides on the parasitic wasp Aphidius ervi. Chemosphere. 54: 619-627.

Desneux, N., A. Decourtye, and J. M. Delpuech. 2007. The sublethal effects of pesticides on beneficial arthropods. Annu. Rev. Entomol. 52: 81-106.

Desneux, N., M. G. Luna, T. Guillemaud, and A. Urbaneja. 2011. The invasive South American tomato pinworm, Tuta absoluta, continues to spread in Afro-Eurasia and beyond: the new threat to tomato world production. J. Pest Sci. 84: 403-408.

El-Wakeil, N. E., N. Gaafar, and S. Vidal. 2006. Side effect of some neem products on natural enemies of Helicoverpa (Trichogramma spp.) and Chrysoperla carnea. Arch. Phytopathology Plant Protect. 39: 445-455.

FAOSTAT. 2014. FAO statistical databases. Food and Agriculture Organization of the United Nations, Rome, Italy. http://www.fao.org/ faostat/en/\#data/QC.

Garcia, P. V., N. Pereira, and L. M. Oliveira. 2009. Side-effects of organic and synthetic pesticides on cold-stored diapausing prepupae of Trichogramma cordubensis. BioControl. 54: 451-458.

Ghorbani, M., M. Saber, M. Bagheri, and N. Vaez. 2016. Effects of diazinon and fipronil on different developmental stages of Trichogramma brassicae Bezdenko (Hym.; Trichogrammatidae). J. Agr. Sci. Tech. 18: 1267-1278.

Hassan, S. A. 1992. Guideline for the evaluation of side-effects of plant protection product on Trichogramma cacoeciae. IOBC/WPRS Bull. XV/3, 18-39.

Hassan, S. A. 1994. Comparison of three different laboratory methods and one semi-field test method to assess the side effects of pesticides on Trichogramma cacoeciae Marchal (Hym., Trichogrammatidae). IOBC/ WPRS Bull. 17: 133-141.

Hassan, S. A., B. O. Haves, P. E. Degrande, and K. Herai. 1998. The side-effects of pesticides on the egg parasitoid Trichogramma cacoeciae Marchal (Hym., Trichogrammatidae), acute dose-response and persistence tests. J. Appl. Entomol. 122: 569-573.

Hewa-Kapuge, S., S. McDougall, and A. A. Hoffmann. 2003. Effects of methoxyfenozide, indoxacarb, and other insecticides on the beneficial egg parasitoid Trichogramma nr. brassicae (Hymenoptera: Trichogrammatidae) under laboratory and field conditions. J. Econ. Entomol. 96: 1083-1090.

Hussain, D., M. Akram, Z. Iqbal, A. Ali, and M. Saleem. 2010. Effect of some insecticides on Trichogramma chilonis (Ishii) (Trichogrammatidae: Hymenoptera) immature and adult survival. J. Agric. Res. 48: 531-537.

IBM. 2015. IBM SPSS statistics for Windows, Version 23.0. IBM Corp, Armonk, NY.

Jeschke, P., and R. Nauen. 2008. Neonicotinoids-from zero to hero in insecticide chemistry. Pest Manag. Sci. 64: 1084-1098.

Khan, M. A., H. Khan, A. Farid, and A. Ali. 2015. Evaluation of toxicity of some novel pesticides to parasitism by Trichogramma chilonis (Hymenoptera: Trichogrammatidae). J. Agric. Res. 53: 63-73.

Khattak, M. K., and M. Mamoon-ur-Rashid. 2006. Evaluation of neem (Azadirachta indica A. Juss) oil, neem seed water extracts and baythroid TM against bollworms and egg parasitoid Trichogramma chilonis. Pak. Entomol. 28: 5-9.

Ksentini, I., T. Jardak, and N. Zeghal. 2010. Bacillus thuringiensis, deltamethrin and spinosad side-effects on three Trichogramma species. Bull. Insectology. 63: 31-37.

Li, K. H., X. Xu, Y. F. Li, Q. Z. Meng, and L. C. Zhou. 1986. Determination of toxicity of 29 chemicals to Trichogramma japonicum at various developmental stages. Nat. Enemies of Insects. 8: 187-194.

Lira, A. C., O. Z. Zanardi, V. H. Beloti, G. P. Bordini, P. T. Yamamoto, J. R. Parra, and G. A. Carvalho. 2015. Lethal and sublethal impacts of acaricides on Tamarixia radiata (Hemiptera: Eulophidae), an important ectoparasitoid of Diaphorina citri (Hemiptera: Liviidae). J. Econ. Entomol. 108: 2278-2288.

Millar, N. S., and I. Denholm. 2007. Nicotinic acetylcholine receptors: targets for commercially important insecticides. Invert. Neurosci. 7: 53-66.

Moens, J., L. Tirry, and P. Clercq. 2012. Susceptibility of cocooned pupae and adults of the parasitoid Microplitis mediator to selected insecticides. Phytoparasitica. 40: 5-9.
Momanyi, G., R. Maranga, S. Sithanantham, S. Agong, C. S. Matoka, and S. A. Hassan. 2012. Evaluation of persistence and relative toxicity of some pest control products to adults of two native trichogrammatid species in Kenya. BioControl. 57: 591-601.

Moura, A. P., G. A. Carvalho, and R. L. O. Rigitano. 2005. Toxicidade de inseticidas utilizados na cultura do tomateiro a Trichogramma pretiosum. Pesq. Agropec. Bras. 40: 203-210.

Moura, A. P., G. A. Carvalho, A. E. Pereira, and L. C. D. Rocha. 2006. Selectivity evaluation of insecticides used to control tomato pests to Trichogramma pretiosum. BioControl. 51: 769-778.

Musser, F. R., J. P. Nyrop, and A. M. Shelton. 2006. Integrating biological and chemical controls in decision making: European corn borer (Lepidoptera: Crambidae) control in sweet corn as an example. J. Econ. Entomol. 99: 1538-1549.

Nadimi, A., K. Kamali, M. Arbabi, and F. Abdoli. 2008. Side-effects of three acaricides on the predatory mite, Phytoseiulus persimilis Athias-Henriot (Acari: Phytoseiidae) under laboratory conditions. Mun. Ent. Zool. 3: 556-567.

Pisa, L., D. Goulson, E. C. Yang, D. Gibbons, F. Sánchez-Bayo, E. Mitchell, A. Aebi, J. van der Sluijs, C. J. K. MacQuarrie, C. Giorio, et al. 2017. An update of the Worldwide Integrated Assessment (WIA) on systemic insecticides. Part 2: impacts on organisms and ecosystems. Environ Sci Pollut Res. doi:10.1007/s11356-017-0341-3.

Polaszek, A., P. F. Rugman-Jones, R. Stouthamer, E. Hernández-Suárez, T. Cabello, and M. del Pino-Pérez. 2012. Molecular and morphological diagnoses of five species of Trichogramma: biological control agents of Chrysodeixis chalcites (Lepidoptera: Noctuidae) and Tuta absoluta (Lepidoptera: Gelechiidae) in the Canary Islands. BioControl. 57: 21-35.

Pratissoli, D., A. M. Milanez, W. F. Barbosa, F. N. Celestino, G. S. Andrade, and R. A. Polanczyk. 2010. Side effects of fungicides used in Cucurbitaceous crop on Trichogramma atopovirilia Oatman and Platner (Hymenoptera: Trichogrammatidae). Chil. J. Agric. Res. 70: 323-327.

Preetha, G., J. Stanley, S. Suresh, S. Kuttalam, and R. Samiyappan. 2009. Toxicity of selected insecticides to Trichogramma chilonis: assessing their safety in the rice ecosystem. Phytoparasitica. 37: 209-215.

Preetha, G., J. Stanley, S. Suresh, and R. Samiyappan. 2010. Risk assessment of insecticides used in rice on miridbug, Cyrtorhinus lividipennis Reuter, the important predator of brown planthopper, Nilaparvata lugens (Stal.). Chemosphere. 80: 498-503.

Roubos, C. R., C. Rodriguez-Saona, and R. Isaacs. 2014. Mitigating the effects of insecticides on arthropod biological control at field and landscape scales. Biol. Control. 75: 28-38.

Saber, M. 2011. Acute and population level toxicity of imidacloprid and fenpyroximate on an important egg parasitoid, Trichogramma cacoeciae (Hymenoptera: Trichogrammatidae). Ecotoxicology. 20: 1476-1484.

Silva, D. M., and A. F. Bueno. 2015. Organic products selectivity for Trichogramma pretiosum (Hymenoptera: Trichogrammatidae). Arq. Inst. Biol. 82: 1-8.

Simon-Delso, N., V. Amaral-Rogers, L. P. Belzunces, J. M. Bonmatin, M. Chagnon, C. Downs, L. Furlan, D. W. Gibbons, C. Giorio, V. Girolami, et al. 2015. Systemic insecticides (neonicotinoids and fipronil): trends, uses, mode of action and metabolites. Environ. Sci. Pollut. Res. Int. 22: 5-34.

Souza, J. R., G. A. Carvalho, A. P. Moura, M. H. G. Couto, and J. B. Maia. 2014. Toxicity of some insecticides used in maize crop on Trichogramma pretiosum (Hymenoptera, Trichogrammatidae) immature stages. Chil. J. Agric. Res. 74: 234-239.

Takada, Y., S. Kawamura, and T. Tanaka. 2001. Effects of various insecticides on the development of the egg parasitoid Trichogramma dendrolimi (Hymenoptera: Trichogrammatidae). J. Econ. Entomol. 94: 1340-1343.

Thomson, L. J., D. C. Glenn, and A. Hoffmann. 2001. Effects of sulfur on Trichogramma egg parasitoids in vineyards: measuring toxic effects and establishing release windows. Anim. Prod. Sc. 40: 1165-1171.

Thubru, D. P., D. M. Firake, and G. T. Behere. 2016. Assessing risks of pesticides targeting lepidopteran pests in cruciferous ecosystems to eggs parasitoid, Trichogramma brassicae (Bezdenko). Saudi J. Bio. Sci. doi:10.1016/j. sjbs.2016.04.007

Tomizawa, M., and J. E. Casida. 2003. Selective toxicity of neonicotinoids attributable to specificity of insect and mammalian nicotinic receptors. Annu. Rev. Entomol. 48: 339-364. 
Uma, S., S. Jacob, and K. R. Lyla. 2014. Acute contact toxicity of selected conventional and novel insecticides to Trichogramma japonicum Ashmead (Hymenoptera: Trichogrammatidae). Jbiopest. 7: 133-136.

Vieira, A., L. Oliveira, and P. Garcia. 2001. Effects of conventional pesticides on the preimaginal developmental stages and on adults of Trichogramma cordubensis (Hymenoptera: Trichogrammatidae). Biocontrol Sci. Technol. 11: 527-534.

Wang, D. H. Y., X. Guo, and Y. Luo. 2012. Acute toxicities and sublethal effects of some conventional insecticides on Trichogramma chilonis (Hymenoptera: Trichogrammatidae). J. Econ. Entomol. 105: 1104-1476.
Williams, L., and L. Price. 2004. A space-efficient contact toxicity bioassay for minute Hymenoptera, used to test the effects of novel and conventional insecticides on the egg parasitoids Anaphes iole and Trichogramma pretiosum. BioControl. 49: 163-185.

Zar, J. H. 1996. Biostatistical analysis. Prentice-Hall International Editions, London, United Kingdom.

Zhu, J. S., M. L. Lian, J. Wang, and S. Qin. 2009. Toxicity and safety evaluation of five insecticides on egg parasitoid, Trichogramma evanescens Westwood. Chin. J. Eco-Agric. 17: 715-720. 